\title{
CORRELATION OF TRIPLE VESSEL DISEASE WITH TIMI SCORE IN NON-ST SEGMENT ELEVATION MYOCARDIAL INFARCTION.
}

1. MBBS, FCPS (Medicine) Assistant Professor Department of Medicine Quaid E Azam Medical College, Bahawalpur.

2. MBBS, FCPS (Cardiology) Senior Registrar Department of Cardiology/CCU QAMC/BVH, Bahawalpur.

3. MBBS, FCPS (Cardiology), FACC, MCPS-HPE

Associate Professo Department of Cardiology Quaid E Azam Medical College, Bahawalpur.

Correspondence Address: Dr. Akram Ehsan,

41-C Medical Colony, Bahawalpur. dr.akramahsan@gmail.com

Article received on:

26/07/2018

Accepted for publication:

15/01/2019

Received after proof reading: 25/06/2019
Muhammad Akram 1 , Muhammad Atif Malik ${ }^{2}$, Shahadat Hussain Ch. ${ }^{3}$

ABSTRACT... The purpose of this study was to determine the correlation of Triple Vessel Disease with TIMI score in patients of Non ST segment elevation Myocardial Infarction. Study Design: Descriptive cross sectional study. Setting: Study was conducted in the Department of Cardiology, Bahawal Victoria Hospital, Bahawalpur Period: From 01-01-2017 to 31-12-2017. Materials and Methods: A total of 150 patients with NSTEMI of age 20-65 years of either gender were included in the study. TIMI score calculation was done in every patient and each patient was graded from 0-7. All the patients underwent through coronary angiography to determine the involvement of coronary arteries. Variables used were TIMI score, BMI and extent of disease diagnosed by Angiography. The data was collected and analyzed with SPSS V20. Results: Mean age was $38.70 \pm 6.37$ years in our study. Out of the 150 patients, $128(85.33 \%)$ were male and $22(14.67 \%)$ were females with ratio of 5.8:1. Mean height was $171.32 \pm 14.38 \mathrm{~m}$. Mean weight was $81.36 \pm 17.62 \mathrm{~kg}$. Mean BMl was $29.75 \pm 4.89 \mathrm{~kg} / \mathrm{m}^{2}$. Three vessel involvements were in $98(65.33 \%)$ patients, whereas two vessel, one vessel and normal. Conclusion: The TIMI scoring system is ideal, realistic and practically easy to use at the patient bedside. It suggests a high frequency (65.33\%) of Triple Vessel Disease, in patients with Non-ST segment elevation myocardial infarction (NSTEMI), if TIMI score is $>4$.

Key words: $\quad$ Hypertension, Multi-Vessel Disease, Non-ST Elevation MI, STEMI, TIMI Score.

Article Citation: Akram M, Malik MA, Ch. SH. Correlation of triple vessel disease with TIMI score in Non-ST segment elevation myocardial infarction. Professional Med J 2019; 26(3):1136-1140. DOI: 10.29309/TPMJ/2019.26.07.3785

\section{INTRODUCTION}

Acute coronary syndrome (ACS) is a clinical presentation that ranges from ST-segment elevation myocardial infarction (STEMI) to presentations found in non-ST-segment elevation myocardial infarction (NSTEMI) or in unstable angina. ${ }^{1}$ It is classified into two types according to the appearance of the electrocardiogram (ECG/ EKG), non-ST segment elevation myocardial infarction (NSTEMI) and ST segment elevation myocardial infarction (STEMI). ${ }^{2}$ Its most common symptom is chest pain, often radiating to the left arm or angle of the jaw and associated with nausea and sweating. In NSTE ACS, ECG may be normal, and according to some studies about 5\% patients having normal ECG and were discharged, ultimately develop acute myocardial infarction (MI). ${ }^{3}$ Acute coronary syndrome should be differentiated from stable angina, which develops during exertion and disappear at rest.
Unstable angina occurs suddenly, usually at rest or with minimal exertion. New onset angina is also categorized unstable angina, as it suggests a new problem in the coronary artery.

NSTE-ACS is more common than STE-ACS and the annual incidence is 73 per $1000,{ }^{3}$ with $3-5 \%$ mortality. ${ }^{4}$ Mortality rates are higher among patients with NSTE-ACS than with STE-ACS according to the long term follow up. Advancing age, male gender, smoking, co-morbid states like diabetes mellitus (DM), hypertension (HTN) are the risk factors which increase the morbidity and mortality after Acute Myocardial Infarction and help us to find out its prognosis. ${ }^{5}$

Therefore primary prevention is to control these risk factors, doing exercise regularly, eating healthy food, avoid smoking and control of hypertension, diabetes and controlling cholesterol 
levels in patients with significant risk factors. It has been proved that use of aspirin also reduce the risk of cardiovascular events. ${ }^{6}$

To stratify the risk in these patients after an episode of myocardial infarction various scoring systems have been developed. For the prediction of mortality in these patients TIMI score is used widely. A study by Lakhani MS, et al, showed that patients with TIMI $\square 4$ had high frequency of three vessel disease. This was the single study available in literature. Before that no previous study was done in this regard. Its results needed to be verified by further studies. There is also no local study available in local population. By applying TIMI score might help us in recognizing the high risk population with three vessel disease. So, early recognition and prompt treatment could be offered to the patients with NSTEMI.

\section{MATERIAL AND METHODS}

Our study was descriptive Cross Sectional which was conducted in the Cardiology department of Bahawal Victoria Hospital, Bahawalpur. Its Duration was 1 year from 01-01-2017 to 31-122017. Sampling technique was Non-probability, Consecutive sampling. All patients with NSTEMI having age 20-65 years with history of chest pain at rest for more than 10 minutes without STsegment elevation in ECG and positive Troponin $\mathrm{T}$ were included in the study. The Patients with percutaneous coronary intervention $(\mathrm{PCl})$, previous coronary artery bypass grafting (CABG), hemodynamically unstable (BP $<90 / 60 \mathrm{~mm}$ of $\mathrm{Hg}$ ) and with NSTEMI who were treated in some other unit and then referred to our ward were excluded from the study.

After permission from the ethical review committee, total number of 150 patients with Non ST segment elevation myocardial infarction (NSTEMI) admitted to the department of cardiology Bahawal Victoria Hospital Bahawalpur fulfilling the Inclusion/ Exclusion criteria were selected. Demographic history including age (in years), sex (male or female), weight and height of each patient were noted. Informed consent was taken from patients. TIMI score calculation was done in every patient based on the following parameters i.e. age, risk factors for CAD (diabetes mellitus, hypertension, smoking, hyperlipidemia, and family history), significant coronary stenosis(>70\% stenosis), STsegment deviation, cardiac markers of necrosis, severe anginal symptoms and prior use of aspirin Table-I. In this way, each patient was graded from 0-7. All the patients were undergone through coronary angiography to determine if there was any three vessel disease (presence on coronary angiography ( $\geq 70 \%$ stenosis in 3 major vessels) which labeled as yes or no. The data was collected in specially designed Performa.

All the collected data was entered into SPSS version 20 and analyzed. Frequencies were calculated for qualitative data like demographics male or female, triple vessel disease $>4$ TIMI score. Quantitative data like age (in years), weight, height and BMI were presented as means and standard deviations. Effect modifiers like age, sex and BMI were controlled by stratification of data with triple vessel disease. Chi-square test was applied. $P<0.05$ was taken as statistically significant. All the collected data was entered into SPSS version 20 and analyzed. Qualitative data like demographic (sex, male or female), triple vessel disease, TIMI score $>4$ were presented in the form of Frequency and proportion. Quantitative data like age, weight, height and BMI were presented as means $\pm 1 S D$.

\section{RESULTS}

The Age of patients in our study range from 20 to 65 years with mean age $38.70 \pm 6.37$ years. Most of the patients 77 (51.33\%) were between 41 to 45 years of age as it is shown in Table-Il. According to body mass index (BMI) 91 (60.67\%) were with $<27 \mathrm{~kg} / \mathrm{m}^{2}$ and 59 (39.33\%) with $>27 \mathrm{~kg} / \mathrm{m}^{2}$.

TIMI scoring (Table-I) of all patients included in the study was done and then coronary angiography was performed. Triple vessel disease was found in 98 (65.33\%) patients, whereas there was no triple vessel disease in 52 (34.67\%) patients. When Stratification was done on age groups with respect to triple vessel disease, it was found that there was significant difference $(p=0.000)$ of triple vessel disease between different age groups as shown in Table-II. While gender stratification 
has shown no statistically significant difference. Stratification of BMI with respect to triple vessel disease has shown in Table-Il which showed statistically significant difference $(p=0.023)$.

\section{DISCUSSION}

Myocardial infarctions occur when a coronary artery is blocked suddenly by a blood clot and at least some of the heart muscle which is supplied by that artery is infarcted. Myocardial infarctions are of two types, depending upon the severity. NSTEMI is the less severe ${ }^{2}$, in which the blood clot only partly occludes the artery, and only a portion of the heart muscle which is supplied by the affected artery is infarcted. In comparison to the more severe type of Myocardial Infarction the STEMI, the NSTEMI do not produce characteristic elevation in the "ST segment" portion of the ECG. (ST segment elevation indicates that a relatively large portion of heart muscle is infarcted as the coronary artery is totally occluded).

It has been seen in recent studies that majority (54\%) of acute MI patients admitted to the hospital have NSTEMI. ${ }^{7}$ Current study also showed that patients with NSTEMI had higher 1 year mortality (31\%) as compared to patients with ST-elevation MI (21\%). Patients with NSTEMI are usually older with poor left ventricle function, multi vessel disease and have history of acute coronary problems. Triple vessel disease was defined as $70 \%$ or greater stenosis in at least one major epicardial vessel and $50 \%$ or greater stenosis in at least one other major vessel. The segments of vessels analyzed in the patients include, the proximal, middle, and distal right coronary artery, the proximal and middle left anterior descending artery, the first diagonal left anterior descending artery, the proximal and distal left circumflex artery, and first and second obtuse marginals. ${ }^{8}$

Assessment of the risk is crucial in patients with ACS for predicting the clinical outcome and to determine the treatment strategy. Many clinical and laboratory parameters have been used to find out the risk for the patients. The most commonly used risk score is the TIMI risk score. It reflect the early and long-term adverse clinical outcome.

It is simple to use and can provide a prognostic index like mortality among the patients. ${ }^{9,10}$ We have conducted this study to find out the frequency of Three Vessel Disease on the basis of TIMI score $>4$ in patients with Non ST segment elevation myocardial infarction (NSTEMI). In our study range of age in patients was from 20 to 65 years with mean age of $38.70 \pm 6.37$ years with most of the patients 77 (51.33\%) between 41 to 45 years of age.

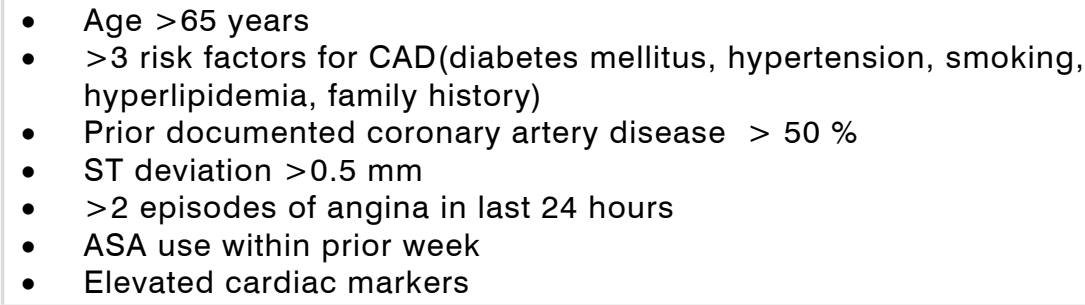

Total Score

\begin{tabular}{|c|c|c|c|c|c|}
\hline \multirow{2}{*}{ Parameters } & \multirow{2}{*}{ Groups } & \multicolumn{3}{|c|}{ Triple Vessel Disease } & \multirow{2}{*}{ P-value } \\
\hline & & Present & Absent & Total & \\
\hline \multirow{2}{*}{ Age } & $20-30$ & 01 (3.85\%) & $25(96.15 \%)$ & 26 & \multirow{2}{*}{0.000} \\
\hline & $41-45$ & 40 (51.95\%) & 37 (48.05\%) & 77 & \\
\hline BMI & $<27 \mathrm{Kg} / \mathrm{m}^{2}$ & $14(23.73 \%)$ & 45 (76.27\%) & 56 & 0.023 \\
\hline
\end{tabular}


AL-Saffar $\mathrm{H}$ et $\mathrm{al}^{11}$ and Lakhani $\mathrm{MS}$ et $\mathrm{al}^{12}$ in their studies had found much larger mean age i.e. 56 and 64 years while Ahmad $Z$ et al ${ }^{13}$ reported lower mean age i.e. 33 years in his study compared to our study. This lower mean age in our study may be due to lower age range as compared to other studies discussed above.

Acute myocardial infarction predominantly affect the males but in recent years the incidence of $\mathrm{MI}$ in women is also increasing. In the current study, we have found a male predominance $(85.33 \%$ were male and $14.67 \%$ were females with ratio of 5.8:1) as was also observed in many previous studies. ${ }^{2,8,14,15,16}$ In our study, the percentage of patients according to body mass index (BMI) was $91(60.67 \%)$ with $>27 \mathrm{~kg} / \mathrm{m}^{2}$ and 59 (39.33\%) with $<27 \mathrm{~kg} / \mathrm{m}^{2}$ with mean BMI was $29.75 \pm 4.89 \mathrm{~kg} /$ $\mathrm{m}^{2}$. Higher body mass index (BMI) was because of reduce physical activity. ${ }^{17}$ Exercise increases insulin sensitivity and $H D L-C$, reduces $B P$ as well as obesity and endothelial function is also improved. Regular exercise and brisk walk for 35 to 40 minutes has been associated with $50 \%$ reduction in cardiac diseases. ${ }^{18}$

Triple vessel disease was found in 98 (65.33\%) patients, whereas there was no triple vessel disease in 52 (34.67\%) patients in our study. A study done by Lakhani MS et al, ${ }^{12}$ concluded that patients with TIMI score $>4$ were at more risk to have significant three vessel CAD (62\%) as compared to those with TIMI risk score $<4$ (46.2 $\%)$ with statistically significant $p$ value $(<0.05)$. In another study, Mega $\mathrm{JL}$ et $\mathrm{al}^{18}$ found that patients of NSTEMI with TIMI risk score of $>5$ were at more risk to have triple vessel disease and reported frequency of $80 \%$. Similarly, Garcia S et $\mathrm{al}^{19}$ also concluded that the frequency of triple vessel disease in NSTEMI patients increases as TIMI score increases.

The TIMI risk score was developed for patients with unstable angina and non-ST elevation myocardial infarction. The TIMI risk score is used for objective risk stratification of patients. The risk corresponds to future cardiac events and identifies the patients who can get benefit from an early invasive strategy. ${ }^{20}$ In a study by Isilak $Z$ et $\mathrm{al}^{21}$ triple vessel disease in NSTEMI patients was found in $65.5 \%$ patients which is quite similar to findings of our study.

\section{CONCLUSION}

This study concluded that TIMI scoring system is practical and easy to use at the patient bedside and there is high frequency $(65.33 \%)$ of Triple Vessel Disease in patients with Non ST segment elevation myocardial infarction (NSTEMI) with TIMI score $>4$. Moreover, it has positive association with age and body mass index (BMI). So, we recommend that TIMI scoring system should be applied in every patient presented with NSTEMI for early recognition of this high risk group with triple vessel disease and prompt treatment could be offered to these patients.

Copyright $@ 15$ Jan, 2019.

\section{REFERENCES}

1. O'Connor RE, Bossaert L, Arntz HR, Brooks SC, Diercks D, Feitosa-Filho G, et al. Part 9: Acute coronary syndromes: 2010 International consensus on cardiopulmonary resuscitation and emergency cardiovascular care science with treatment recommendations. Circulation. 2010; 122:422-65.

2. Daga LC, Kaul U, Mansoor A. Approach to STEMI and NSTEMI. J Assoc Physic India. 2010; 59:19-25.

3. Fox KA, Eagle KA, Gore JM, Steg PG, Anderson FA. The global registry of acute coronary events, 1999 to 2009-GRACE. Heart. 2010; 96:1095-101.

4. Yeh RW, Sidney S, Chandra M, Sorel M, Selby JV, Go AS. Population trends in the incidence and outcomes of acute myocardial infarction. N Engl J Med. 2010; 62:2155-65.

5. Hamm CW, Bassand JP, Agewall S, Bax J, Boersma E, Bueno $\mathrm{H}$, et al. ESC Guidelines for the management of acute coronary syndromes in patients presenting without persistent ST-segment elevation. Euro Heart J. 2011; 32:2999-3054.

6. Grech ED, Ramsdale DR. Acute coronary syndrome: Unstable angina and non-ST segment elevation myocardial infarction. $\mathrm{Br}$ Med J. 2003; 326 (7401):1259-61.

7. Gurm HS, Gore JM, Anderson FA Jr, et al. Comparison of acute coronary syndrome in patients receiving versus not receiving chronic dialysis (from the global registry of acute coronary events [Grace] registry). Am J Cardiol. 2012; 109(1):19-25. 
8. Damman P, Holmvang L, Tijssen JG. Usefulness of the admission electrocardiogram to predict longterm outcomes after non-st-elevation acute coronary syndrome (from the FRISC II, ICTUS, and RITA-3 [FIR] Trials). Am J Cardiol. 2012; 109(1):6-12.

9. Reeder GS, Holmes DR, Detre K, Costigan T, Kelsey SF. The National heart, lung, and blood institute percutaneous trans luminal coronary degree of revascularization in patients with multivessel coronary disease: A report from angioplasty registry. Circulation. 1988; 77:638-44.

10. Waxman DA, Hecht S, Schappert J, Husk G. A model for troponin I as a quantitative predictor of in-hospital mortality. J Am Coll Cardiol. 2006; 48:1755-62.

11. Al-Saffar $\mathrm{H}$, Nasser $\mathrm{H}, \mathrm{Al}-\mathrm{Sh}$ aibii A A. Coronary artery ectasia in ischemic heart disease patients. Iraqi Postgrad Med J. 2012; 2:622-29.

12. Lakhani MS, Qadir F, Khan M, Hanif B, Farooq HS. Correlation of Thrombolysis in Myocardial Infarction (TIMI) risk score with extent of coronary artery disease in patients with acute coronary syndrome. $\mathrm{J}$ Pak Med Assoc. 2010; 60:197.

13. Westerhout CM, Fu Y, Lauer MS. Short-and long-term risk stratification in acute coronary syndromes: the added value of quantitative ST-segment depression and multiple biomarkers. J Am Coll Cardiol. 2006; 48:939-47.

14. Chughtai $H$, Ratner D, Pozo M, et al. Prehospital delay and its impact on time to treatment in ST-elevation myocardial infarction. $A m J$ Emerg Med. 2011; 29(4):396-400.
15. García-Almagro FJ, Gimeno JR, Villegas M, Hurtado J, Teruel F, Cerdán MC, et al. Prognostic value of the thrombolysis in myocardial infarction risk score in a unselected population with chest pain. Construction of a new predictive model. Am J Emerg Med. 2008; 26:439-45.

16. Waxman DA, Hecht S, Schappert J, Husk G. A model for troponin I as a quantitative predictor of in-hospital mortality. J Am Coll Cardiol. 2006; 48:1755-62.

17. Carrie D, Elbaz M, Puel J. Five-year outcome after coronary angioplasty versus bypass surgery in multivessel coronary artery disease: Results from the french monocentric study. Circulation. 1997; 96:II$1-\mid I-6$.

18. Al-Saffar $\mathrm{H}$, Nasser $\mathrm{H}, \mathrm{Al}$-Shaibii A A. Coronary artery ectasia in ischemic heart disease patients. Iraqi Postgrad Med J. 2012; 2:622-29.

19. Rastogi T, Vaz M, Spiegelman D. Physical activity and risk of coronary heart disease in India. Int J Epidemiol. 2004; 33:759-67.

20. Prashant Joshi, Shofiqul Islam, Prem Pais, srinath Reddy. Risk factors for Early Myocardial Infarction in South Asians compared with individuals in other countries. JAMA. 2010; 297:286-94.

21. Isilak Z, Kardesoglu E, Aparci M, Uz O, Yalcin M, Yiginer $\mathrm{O}$, et al. Comparison of clinical risk assessment systems in predicting three-vessel coronary artery disease and angiographic culprit lesion in patients with non-ST segment elevated myocardial infarction/unstable angina pectoris. Kardiol Pol 2012; $70(3): 242-50$.

\begin{tabular}{|c|c|c|c|}
\hline \multicolumn{3}{|c}{ AUTHORSHIP AND CONTRIBUTION DECLARATION } \\
\hline Sr. \# & Author-s Full Name & \multicolumn{1}{c}{ Contribution to the paper } & Author=s Signature \\
\hline 1 & Muhammad Akram & $\begin{array}{l}\text { Theme, data collection and entry, } \\
\text { Content writing. } \\
\text { Data analysis, result writing, } \\
\text { rephrasing the content wrote and } \\
\text { plagiarism. } \\
\text { Data analysis, Supervision, } \\
\text { Guidance, Clinical support and } \\
\text { review. }\end{array}$ \\
\hline
\end{tabular}

